Brit. J. Ophthal. (1956) 40, 225.

\title{
EXPERIMENTAL AND CLINICAL INVESTIGATIONS INTO THE RESISTANCE TO OUTFLOW OF AQUEOUS HUMOUR IN NORMAL SUBJECTS*†
}

\author{
BY
}

\author{
R. WEEKERS, M. WATILLON, AND M. DE RUDDER \\ From the Ophthalmological Clinic, University of Liége (Prof. R. Weekers)
}

THE agreement between data on the resistance to the outflow of the aqueous humour obtained by compression of the eyeball in vivo and those obtained by , perfusion of freshly enucleated eyes shows that tonography yields approximately accurate results.

The normal resistance to outflow in man varies fiom 2.9 to $7.3 \mathrm{~mm}$. $\mathrm{Hg}$, the average being $4 \cdot 5$ (Prijot and Weekers, 1952). Our most recent determinations yielded analogous results (minimum $2 \cdot 1$, maximum $6 \cdot 9$, average $4 \cdot 0$; see below). These figures are in agreement with those given by Grant and Trotter (1955), who established an average coefficient of facility of outflow of $0 \cdot 233$ for normal subjects, i.e. an average resistance of $4 \cdot 29_{+}^{+}$.

On the other hand, using perfusion of freshly enucleated human eyes, Grant and Trotter (1955) found an average facility of outflow of $0 \cdot 27$, i.e. a resistance of $3 \cdot 7$.

François, Rabaey, and Neetens (1955) obtained the following values:

\begin{tabular}{c|c|c|c}
\hline \multirow{2}{*}{ Number of Eyes } & \multicolumn{3}{|c}{ Resistance } \\
\cline { 2 - 4 } & Maximum & Average & Minimum \\
\hline 61 & 2 & 4 & 8.3 \\
\hline
\end{tabular}

The aim of the present investigations is to study certain factors which influence the resistance to outflow of aqueous humour in normal subjects.

\section{Technique}

Resistance to outflow was determined in vivo by tonography. Calculations were made with the aid of the most recent tables on ocular tension (1954) and on tonometric pressure

*Received for publication August 16, 1955.

+This investigation was made with the aid of a grant from the Fonds National Belge de la Recherche Scientifique. TThe American authors determine the "facility of outflow" $(C)$; the European authors determine the resistance to outflow of aqueous humour $(R)$. The resistance to outflow of aqueous humour is the reverse of the facility of outflow $\boldsymbol{R}=\frac{I}{\boldsymbol{C}}$.

Calculation of $R$ has the advantage of indicating more directly the pathogenesis of ocular hypertension: an increase in ocular tension is due to an increase in $R$ or a decrease in $C$. 
(Ballantyne, 1954). The duration of the test was $4 \mathrm{~min}$. Unless 'contraindicated, compression was achieved with a 5.5-g. weight.

Resistance was determined in vitro by perfusion of freshly enucleated bovine eyes.

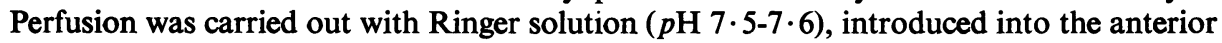
chamber by means of a needle.

Preliminary investigations were made on a number of eyeballs perfused with Ringer's solution, with the addition of fluorescein. Examinations in ultra-violet light revealed that the liquid flowed exclusively at the level of the sectioned aqueous veins. The method is, therefore, suitable for determination of the resistance to the flow between the anterior chamber and the scleral exits.

In the isolated eye, the episcleral venous pressure being absent, the resistance is calculated by dividing the pressure of the perfusion liquid expressed in $\mathrm{mm}$. $\mathrm{Hg}$, by the flow expressed in $\mathrm{mm} \cdot{ }^{3} / \mathrm{min}$.

\section{Results}

(a) Changes in the Resistance to the Outflow of the Aqueous Humour as a Function of Age.-This study covered ninety normal subjects with no family history of glaucoma and without marked ametropia; they were divided into three age groups. Resistance was determined by tonography.

Table I shows a slight increase in resistance to the outflow of the aqueous humour with increased age, which is statistically significant.

TABLE I

INCREASE IN RESISTANCE TO THE OUTFLOW OF THE AQUEOUS HUMOUR AS A FUNCTION OF AGE

\begin{tabular}{|c|c|c|c|c|c|}
\hline \multirow{2}{*}{ Age (yrs) } & & \multirow{2}{*}{ Number of Cases } & \multicolumn{3}{|c|}{ Resistance } \\
\hline & & & Minimum & Average & Maximum \\
\hline Less than $35 \ldots$ & $\ldots$ & 30 & $2 \cdot 1$ & $3 \cdot 68$ & $5 \cdot 0$ \\
\hline From 35 to 55 & $\ldots$ & 30 & $2 \cdot 2$ & 3.95 & $5 \cdot 7$ \\
\hline Over 55 & $\ldots$ & 30 & $2 \cdot 5$ & $4 \cdot 43$ & $6 \cdot 9$ \\
\hline
\end{tabular}

(b) Changes in the Resistance to Outflow resulting from Contraction of the Ciliary Muscle.-Becker (1954) showed that the instillation of pilocarpine reduces the resistance to outflow in normal subjects. Our observations cover thirty normal subjects with no family history of glaucoma and without marked ametropia, which were divided into three age groups.

Contraction of the ciliary muscle was induced by means of eserine. Tonographic determinations were made 2 to 5 hours after instillation of a 1 per cent. oily solution. The pupil was at that moment markedly contracted. The results are presented in Table II, which shows that contraction of the ciliary muscle reduces normal resistance. 
TABLE II

RESISTANCE TO OUTFLOW IN NORMAL SUBJECTS AFTER CONTRACTION OF CIIJIARY MUSCLE INDUCED BY ESERINE

\begin{tabular}{|c|c|c|c|c|c|}
\hline \multirow{2}{*}{\multicolumn{2}{|c|}{ Age (yrs) }} & \multirow{3}{*}{$\begin{array}{c}\text { Number of Cases } \\
10 \\
\end{array}$} & \multicolumn{3}{|c|}{ Resistance } \\
\hline & & & \multirow{2}{*}{$\begin{array}{c}\text { Minimum } \\
2 \cdot 20\end{array}$} & \multirow{2}{*}{$\frac{\text { Average }}{2 \cdot 73}$} & \multirow{2}{*}{$\frac{\text { Maximum }}{4 \cdot 24}$} \\
\hline Under $35 \quad \ldots$ & ... & & & & \\
\hline From 35 to 55 & $\ldots$ & 10 & $2 \cdot 33$ & $3 \cdot 06$ & $3 \cdot 98$ \\
\hline Over 55 & $\ldots$ & 10 & $2 \cdot 33$ & $3 \cdot 18$ & $4 \cdot 75$ \\
\hline
\end{tabular}

A comparison of Tables I and II shows that the reduction applies mainiy to the average and maximum values; the lower limit of physiological resistance remains unaltered. Consequently, the normal values of resistance to outflow are less widely spread after the administration of eserine.

(c) Changes in Resistance to Outflow as a Function of Tonometric Pressure.The investigations covered 85 normal subjects with no family history of glaucoma and without marked ametropia. The subjects were divided into three groups, each group showing the same composition as regards age (juvenile, adult, and aged) in order to eliminate the influence of age (see above).

Tonographic determinations were made using weights of $5.5 \mathrm{~g}$. in the first group, $7 \cdot 5 \mathrm{~g}$. in the second, and $10 \mathrm{~g}$. in the third. The tonometric pressures (initial average values) thus registered were 31,37 , and $43 \mathrm{~mm}$. $\mathrm{Hg}$, respectively.

Table III shows that the resistance to outflow increased with the tonometric pressure exerted during compression. This increase is statistically significant.

TABLE III

INCREASE IN RESISTANCE TO OUTFLOW IN NORMAL SUBJECTS AS A FUNCTION OF TONOMETRIC PRESSURE

\begin{tabular}{c|c|c|c|c}
\hline \multirow{2}{*}{ Weight (g.) } & \multirow{2}{*}{ Number of Cases } & & \multicolumn{2}{c}{ Resistance } \\
\cline { 2 - 4 } & & Minimum & Average & Maximum \\
\hline $5 \cdot 5$ & 30 & $2 \cdot 6$ & $4 \cdot 1$ & $6 \cdot 2$ \\
\hline $7 \cdot 5$ & 29 & $3 \cdot 0$ & $5 \cdot 0$ & $7 \cdot 6$ \\
\hline 10 & 26 & $3 \cdot 5$ & $5 \cdot 5$ & $7 \cdot 8$ \\
\hline
\end{tabular}

In view of difficulties encountered in the interpretation of this observation, we have found it necessary to study the influence of the pressure of the per- 
fusion liquid on the resistance in the enucleated eye. Within the narrow limits of physiological pressure, Bárány $(1954 \mathrm{a}, \mathrm{b})$ found no change in resistance as a function of the pressure of the perfusion liquid. By provoking marked hypertension, we have demonstrated a slight increase in resistance to outflow in bovine eyes due to this cause (Fig. 1).

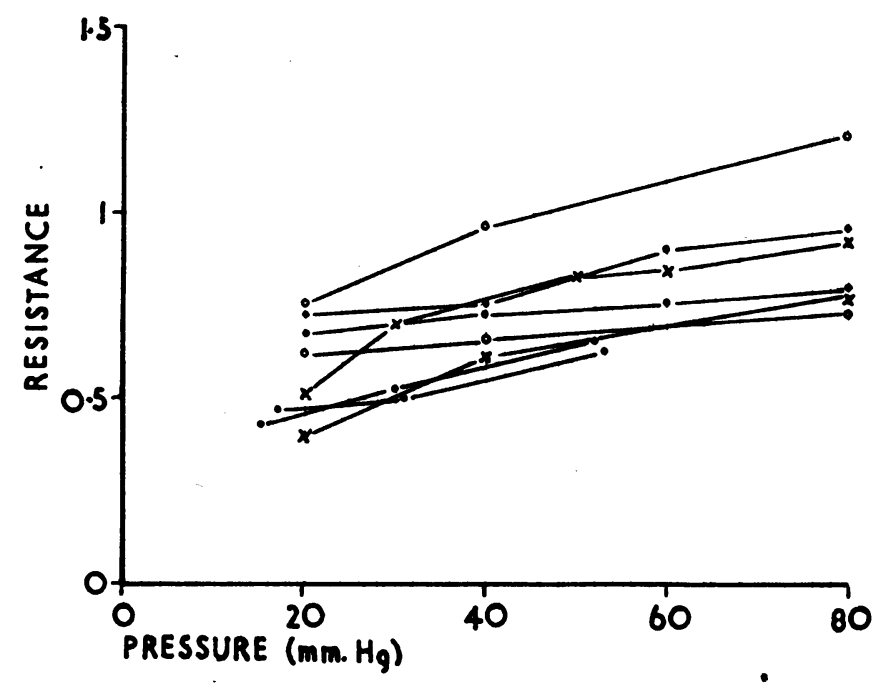

FIG. 1.-Increase in resistance to outflow as a function of the pressure of the perfusion liquid (according to Watillon, Prijot, and Weekers, 1954).

(d) Changes in Resistance to Outflow caused by Hyaluronidase.-Bárány $(1954 a, b)$ made an important contribution to the study of resistance to outflow by demonstrating that hyaluronidase facilitates the outflow of aqueous humour through the outlets of the anterior segment of the bovine eye. This enzyme depolymerizes, hydrolyses, and diminishes the viscosity of hyaluronic acid; its action is clearly suggestive of the presence of hyaluronic acid in the outlets of the anterior segment and, more precisely, in the corneo-scleral trabeculae. The introduction of hyaluronidase, in vivo, into the anterior chamber in human subjects throws no light upon this problem since, on the two occasions wherein we have performed this experiment upon blind eyes, a violent inflammatory reaction resulted, which vitiated the experiment.

A study of the effect of hyaluronidase on the resistance to the outflow of the aqueous humour is, therefore, only possible in enucleated eyes. Observations were made on twenty eyes from adult cattle, divided into two groups of ten. The first group received, before perfusion, an injection of 250 viscosity reducing units of hyaluronidase dissolved in $1 \mathrm{ml}$. Ringer solution. The second group served as controls, receiving $1 \mathrm{ml}$. Ringer solution without hyaluronidase. 
Table IV shows, in agreement with the observations of Bárány, that hyaluronidase considerably reduces the resistance to the outflow of the aqueous humour.

TABLE IV

DIMINUTION OF RESISTANCE TO OUTFLOW DUE TO HYALURONIDASE ACCORDING TO WATILLON, PRIJOT, AND WEEKERS (1954).

Th normal resistance in the ox is considerably lower than in man, because the eyeball is larger.

\begin{tabular}{|c|c|c|c|c|c|}
\hline \multirow{2}{*}{ Series } & & \multirow{2}{*}{ Number of Cases } & \multicolumn{3}{|c|}{ Resistance } \\
\hline & & & Minimum, & Average & Maximum \\
\hline Control . & ... & 10 & $0 \cdot 76$ & 0.93 & $1 \cdot 21$ \\
\hline Hyaluronidase & $\ldots$ & 10 & $0 \cdot 30$ & 0.54 & 0.66 \\
\hline
\end{tabular}

François, Rabaey, and Neetens (1955) recently made.the same observations on 24 enucleated human eyes, the average reduction in resistance being 29 per cent.

\section{Discussion}

Most of these observations have a more or less direct clinical significance, and it is especially from this point of view that they will be discussed. They will be considered with reference to changes in resistance as a function of:
(a) Age
(b) Contraction of the ciliary muscle
(c) Compression of the eyeball
(d) Presence of hyaluronidase.

(a) Investigations made by Goldmann $(1951,1954 a, b)$ sugggested that the resistance to the outflow of the aqueous humour is localized mainly in the scleral trabeculae. Teng, Paton, and Katzin (1955), on the other hand, demonstrated that the trabecular structure is subject to microscopic changes in 12-13 per cent. of subjects over the age of 50. These authors report as follows:

First, the collagen becomes granular, then it disappears. Endothelium, connective tissue cells, and nuclei seem to remain intact. Elastic fibres are more resistant, but they also degenerate eventually. When the degenerative process is completed, the endothelial cells have formed a mass that is either spongy or laminated and resembles a bundle of fibrous tissue cells except that they do not take strain (Fig. 2, overleaf).*

It seems likely that the increase in resistance to outflow as a function of age, and demonstrated by tonography (Table I) may be attributable to the trabecular changes described by Teng, Paton, and Katzin (1955).

Another hypothesis also deserves attention. The corneal and scleral rigidity increases with age. All other conditions being unaltered, this factor could reduce

\footnotetext{
* Our thanks are due to Dr. Teng for his kindness in making available the plate used in Fig. 2 and in authorizing its reproduction.
} 


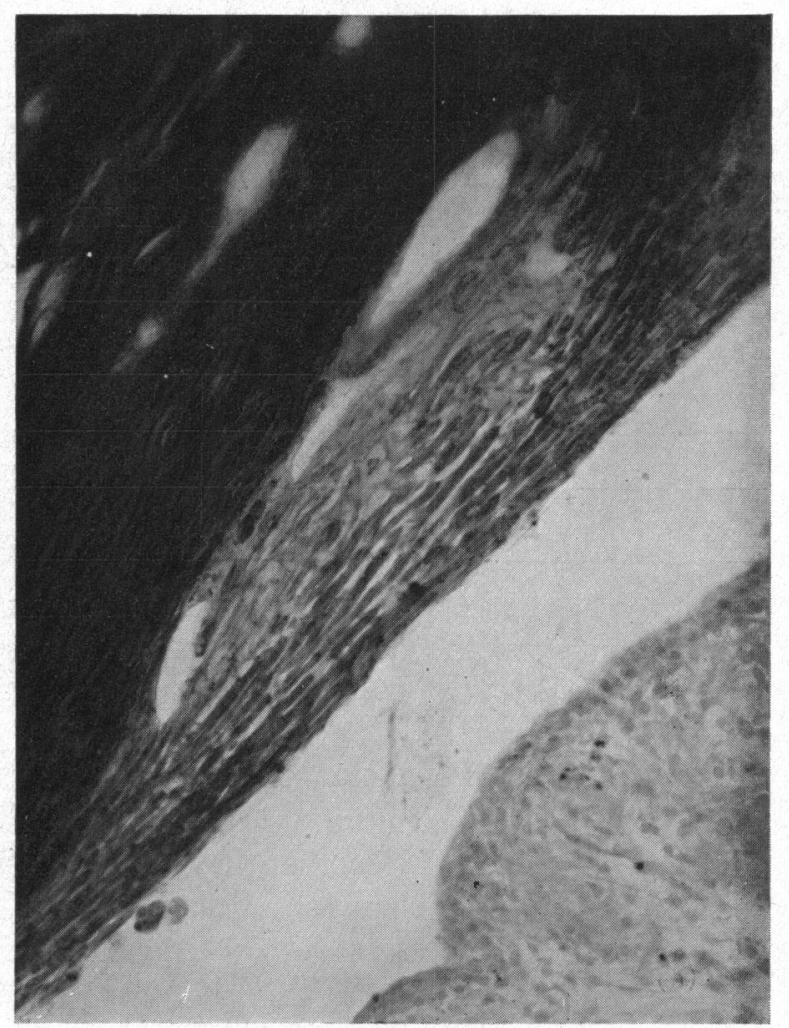

Fig. 2 (according to Teng, Paton, and Katzin, 1955).--Degenerative lesions of external part of trabeculae or internal part of Schlemm's canal in normal aged subjects (Van (iirson).

the corneal indentation caused by the tonometer. This interpretation should be excluded because Goldmann (1951), who calculated resistance on the basis of the fluorometric determination of the flow, also found an increased resistance to outflow as a function of age. Since the corneal and scleral rigidity have no influence on the calculated resistance based on fluorometric determination of the flow, the increased resistance in aged subjects must be attributed to a progressive reduction of the trabecular permeability. This develops without any pathological manifestation and should be taken into account in the clinical tonographic study of pathological increases in resistance.

(b) Becker (1954) has demonstrated that pilocarpine reduces the resistance to outflow in normal subjects; eserine also has a similar effect (Table II). A comparison of Tables I and II shows that the effect of eserine is more marked in subjects with a high resistance, being practically nil in subjects with a low resistance before the instillation of the miotic. These observations may be interpreted as follows. Normally, some trabecular channels are opened, while others are closed. Eserine stimulates the ciliary muscle; this exerts traction on the trabeculae, the 
closed channels open, and the resistance decreases. The distribution of physiological values in normal subjects partly depends on the relative number of open and closed channels. After the administration of eserine, the differences are less because all the trabecular channels are open. The question arises whether it would not be easier to discover a slight pathological increase in resistance after, rather than before, the administration of eserine.

These observations offer a satisfactory explanation of the hypotensive effect of miotics clinically even when the lesions causing the increase in resistance to outflow are irreversible; in this case the miotics may affect those parts of the trabeculae which are still intact, thus diminishing the resistance.

(c) A particularly complex problem is encountered in the mechanism of the changes in resistance as a function of the tonometric pressure. Our observations tend to show that the resistance increases if the pressure exerted during tonography is higher. This phenomenon may be partly due to compression of the trabeculae as a result of excessive pressure (Fig. 1). There are other hypotheses however, which should also be taken into account. Several investigators have observed in tonography that the fall in tonometric pressure is more rapid during the first minute than during subsequent minutes. The cause of this phenomenon is not known; it may be attributable to scleral deformity (Goldmann, 1954), a change in blood pressure (Becker and Friedenwald, 1953) or an outflow of blood from the uvea. Whatever the cause, an error of deficiency arises. If this error is independent of the weight used, its importance, in relative value, decreases as the tonometric pressure increases. The result is a progressive diminution of the error of deficiency and an increase in resistance which is only apparent.

The changes in resistance as a function of tonometric pressure may also be explained by the theory of Goldmann (1954): during tonography, the aqueous humour driven out of the eyeball still possesses kinetic energy at its point of emergence from the sclera. This is manifested, according to circumstances, by an enlargement of the aqueous stream in a laminar vessel, by the transformation of a laminar vein into an aqueous vein, or by an aqueous influx into a blood vessel. Goldmann concludes from this that tonography registers the resistance of the outlets up to the point at which the aqueous humour driven from the eyeball has lost all its kinetic energy, i.e. up to a point localized downstream from the emergence of the aqueous vessels from the sclera. This point should be further from the limbus and nearer to the auricle of the heart when the tonometric pressure is higher.

The pathogenesis of changes in resistance as a function of the tonometric pressure-apparent or factual-is, therefore, still unexplained; this deserves further investigation. In spite of these uncertainties, it seems justifiable from a practical point of view to use, in tonography, a heavier weight when the ocular tension is high. We have recommended a weight which gives an initial deviation of at least three to four graduations in the curves of ocular tension and tonometric pressure, since the precision of measurements is less when the initial deviation is slight (Prijot and Weekers, 1952).

(d) The observations of Bárány (1954a,b), confirmed by Watillon, Prijot, and Weekers (1954; and Table IV) and by François, Rabaey, and Neetens (1955), show 
that the resistance to outflow largely depends on the presence of hyaluronic acid in in the outlets of the anterior segment. Hyaluronidase, by depolymerizing hyaluronic acid and reducing its viscosity, considerably facilitates the outflow of aqueous humour. Are these observations capable of clinical application? Do certain therapeutic reductions in resistance result from depolymerization of hyaluronic acid? Is the increase in resistance in certain forms of glaucoma dependent on the accumulation of hyaluronic acid? At present there is nothing to confirm these hypotheses.

In clinical use, the addition of hyaluronidase slightly increases the hypotensive effect of retrobulbar injection of an anaesthetic. This phenomenon does not result from a reduction of the resistance by hyaluronidase. When injected into the orbit, this enzyme does not penetrate the eyeball. Injected without an anaesthetic it has, in fact, no hypotensive action, but mixed with an anaesthetic it enhances the hypotensive effect of the latter by promoting its intra-ocular penetration. The anaesthetic lowers the ocular tension by reducing the production of aqueous humour (DeRoetth and Carroll, 1955).

Investigations made by various authors, and the observations related in this paper, have shown that the resistance to the outflow of the aqueous humour offered by the outlets of the anterior segment may show changes apart from any pathological condition: it increases with age, it is influenced by the contractions of the ciliary muscle, and it is reduced by hyaluronidase.

On the other hand, it is probable that the flow of aqueous humour changes from hour to hour in the course of the day. Fluorometric determination of the flow requires several hours of observation. Rapid determinations, if these were possible, might demonstrate fluctuations which are the probable cause of the diurnal changes in tension.

The ocular tension is essentially dependent upon the flow of aqueous humour on the one hand, and the resistance to the outflow of aqueous humour on the other, i.e. on two factors both susceptible to certain changes. The question arises whether stability is ensured by a regulator phenomenon. Experimental investigations made by Bárány $(1954 a, b)$ tend to show that a diminution of the flow of aqueous humour provokes a compensatory increase in the resistance. Tonography is not yet sufficiently exact to allow a study of this homeostatic phenomenon in clinical cases.

\section{Summary}

(a) The resistance to the outflow of the aqueous humour increases with age, apart from any demonstrable pathological changes.

(b) Contraction of the ciliary muscle provoked by eserine lowers the resistance to the outflow of the aqueous humour.

(c) The resistance to the outflow increases or seems to increase as a function of the tonometric pressure exerted during tonography.

(d) The authors confirmed the observations of Bárány (1954a,b) regarding 
the diminution of the resistance to the outflow resulting from the administration of hyaluronidase.

\section{REFERENCES}

Ballantyne, E. J. (1954). " Clinical Tonography". Cleveland.

BÁrÁNY, E. H. (1954a). Acta Soc. Med. upsalien, 59, 260. (1954b). In " Glaucoma. A Symposium organized by the C.I.O.M.S. ", ed. S. DukeElder, p. 91. Bláckwell, Oxford. and Scotchbrook, S. (1954). Acta physiol. scand., 30, 240.

Becker, B. (1954). Communication of Prof. J. S. Friedenwald to the "Symposium on Glaucoma organized by the C.I.O.M.S.", Ste Marguerite, Quebec, Canada.

and FriedenWALD, J. S. (1953). A.M.A. Arch. Ophthal., 50, 557.

DeRoetth, A., and Carroll, F. D. (1955). Ibid., 53, 399.

FrançoIs, J., RABAEY, M., and NeETENS, A. (1955). Unpublished observations.

GoldmanN, H. (1951). Docum. ophthal., 6-7, 278. (1954a). In "Glaucoma. A Symposium organized by the C.I.O.M.S.", ed. S. DukeElder, p. 105. Blackwell, Oxford.

(1954b). XVII International Congress of Ophthalmology, New York", vol. 3, p. 1573.

Grant, W. M., and TrotTer, R. R. (1955). A.M.A. Arch. Ophthal., 53, 191.

PrIJOT, E., and WeEkers, R. (1952). Ophthalmologica (Basel), 123, 1.

Teng, C. C., Paton, R. T., and Katzin, H. M. (1955). Amer. J. Ophthal., 40, 619.

Watillon, M., Prijot, E., and Weekers, R. (1954). Bull. Soc. belge ophtal., No. 107, p. 374. 